\title{
An Investigation About Misconceptions in Force and Motion in High School
}

\begin{abstract}
Azita Seyed Fadaei
The Union of Iranian Physics Teachers (UIPT),

Tehran, Iran

\author{
César Mora \\ National Polytechnic Institute, \\ Mexico City, Mexico
}

The purpose of this study is to realize students' misconceptions of force and motion before and after formal (traditional) teaching and their stability for high school students. The participants of the study were 2010 th grade girl students from a secondary school located in Tehran, Iran. In the research, a standard diagnostic test with 30 multiple-choice questions probed student understanding of basic concepts in force and motion to achieve the intended goal. To evaluate the stability of common misconceptions in each item of subjects, we explored and investigated the wrong answered questions in test results for the study sample before and after the study and compared them for every item of test. Analysis of wrong responses to tests mentions that some students' misconceptions of force and motion are stable before and after instruction. Results from pre- and post- tests showed that in some parts of the subject, the formal teaching method has been successful, but for others, has had a negative effect on misconceptions in relation to students' responses to test questions. Therefore, the details of wrong answered questions in force and motion show similar misconceptions among students before and after instruction. Results will help teachers and physics curriculum planners to revise the teaching method and contents of textbooks for related unsuccessful parts in this subject.
\end{abstract}

Keywords: traditional teaching, misconception, force, motion, high school

\section{Introduction}

Every student begins physics with a well-established system of commonsense beliefs about how the physical world works derived from years of personal experience. Over the last decade, physics education research has established that these beliefs play a dominant role in introductory physics. One of the most important subjects in exploring the physical world is mechanics. The most significant commonsense beliefs in mechanics have been firmly held by some of the greatest intellectuals in the past, including Galileo and even Newton. Accordingly, these commonsense beliefs should be regarded as reasonable hypotheses grounded in everyday experience. They happen to be false, but that is not always so easy to prove, especially if they are dismissed without a hearing as ill conventional instruction. These commonsense alternatives are commonly labeled as misconceptions. Researches in some cases have focused on students' misconceptions, from young children to high school students in mechanics, especially in Newton's laws. Newton's laws of motion have a special role in exploring the world. They are important when viewed in conjunction with other fundamental 
concepts in physics. Results from research on student understanding in Newton's laws indicate that certain incorrect ideas about the physical world are common among students of a wide variety of educational levels and ages. A number of studies have been performed to gain a better understanding of how students think about the real world. Most research about Newton's laws is designed to detect student misconceptions or alternative conceptions. Studies show that students have an alternative concept of force and individual students consistently applied alternate concepts of force in different contexts about Newton's laws (Brooke \& Etkina, 2009; Viennot, 1979; Thornton, 1997; Champagne \& Anderson, 1980; McCloskey, Caramazza, \& Green, 1980; Boyle \& Maloney, 1991). Forming a meaningful understanding of Newton's laws of motion is formidably difficult for beginners. A variety of teaching approaches have been developed to try to assist students to develop a meaningful understanding. In this study, we focus on students' misconceptions in Newton's laws at the beginning and at the end of a formal teaching. The purpose is to evaluate the role of physics formal instruction in high school to gain a better understanding of Newtonian world.

\section{Teaching Strategy}

Anecdotal evidence suggests that the general method of teaching introductory physics is often the traditional didactic pedagogy in which the lecturer behaves as an expert who transmits knowledge to the students. It is a teacher-centered approach in which the teacher plays the most significant role in the classroom, students are obedient; they study by listening to the teacher and taking notes quietly. Teachers typically explain the content according to the textbooks and give students notes to copy. The content is inflexible. There are very few students who take part in arguing or discussing ideas in the class, consequently, students do not develop good understandings of physics concepts, and students' interest in physics is low and their development of understanding of physics concepts is limited. In this study, traditional or formal teaching strategy is little or no use of interactive teaching method, relying primarily on passive student lectures and algorithm problem exams. The sample consisted of 20 secondary girl students in Somayeh High School in the region five of Tehran, Iran. The sample was randomly selected from second year students (Level 10) undertaking an introductory mechanics course. The course consists of two 20-minute lecture sections per week.

\section{Research Instrument: Force Concept Inventory (FCI)}

The FCI is an instrument used to assess students' beliefs about force and Newton's laws. It is one of the most reliable and useful physics tests currently available for introductory physics teachers and is the best test currently available to evaluate the effectiveness of instruction in introductory physics courses. Students have many commonsense views about motion both before and after formal instruction. Questions on the FCI test were designed to be meaningful to students without formal training in mechanics and target their preconceptions on the subject. The first impression of most physics professors is that the inventory questions are too trivial to be informative. This turns to shock when they discover how poorly their own students perform on it.

Hestenes, Wells, and Swackhamer (1992) designed the FCI to probe student beliefs about force and how their beliefs compare with the many dimensions of the Newtonian concept. Mazur has used the FCI at Harvard University to evaluate the successfulness of peer instruction (Crouch \& Mazur, 2001). The FCI is usually given at the beginning and at the end of a course. Students tend to score higher on the test when it is taken the second time, following instruction. FCI questions were articulated according to their appropriateness for real life 
presentation of Newton's laws. Most physicists would probably agree that a low score on the FCI test indicates a lack of understanding of the basic concepts of mechanics. It is true, but as a rule, "errors" on the inventory are more informative than "correct" choices.

For this study, we chose to use the FCI to guide us to highlight the addressed misconceptions in questions. As a diagnostic tool, the inventory can be used to identify and classify misconceptions. It is especially valuable for teachers to raise their awareness of misconceptions among their own students, also for evaluating instruction; the inventory is a very accurate and reliable instrument.

The FCI is composed of 30 multiple-choice items. The FCI questionnaire is carefully translated to Persian language by one of the physics teachers in Iran and reviewed by a group of experts. We gave the FCI as the pre-test on the second week of class. We took great care that all question sheets and answer sheets are returned. In order to promote serious effort on the pre-test by students, we explained that although their scores on the pre-test will not count towards the course grade, their scores will be confidentially returned to them and will assist both themselves and their instructors to know the degree and type of effort required for them to understand mechanics. We gave the FCI post-test unannounced near the final week of classes, and preferably as part of the final exam with significant course credit given for post-test performance. Giving course credit probably motivates students to take the post-test more seriously and thereby demonstrate more adequately their understanding, especially if time devoted to the post-test subtracts from time spent on the rest of the final exam.

\section{FCI Analyzing Method for Misconceptions}

The two analyses of pre-test and post-test provide information on different aspects of course effectiveness. A cumulative analysis is used to determine that the instruction increases the likelihood of students acquiring and retaining baseline knowledge. For survey classification and analysis purposes, most researchers define the percentage of FCI correct answers analyzing items for pre- and post- tests.

The first set of data presented here (see Figure 1) provide information about the class average pre- and post- test scores for individual FCI items. The class average (see Table 1) in post-test scores is higher than pre-test scores in many questions (questions 1, 2, 3, 4, 5, 8, 9, 10, 15, 16, 17, 18, 22, 26, 27, 29, and 30), but there are six questions (questions $6,7,11,12,13,19,23,24$, and 28) in which the post-test scores are actually lower than the pre-test scores. This implies that the teaching has had a negative effect in relation to students' responses to these questions. In these questions, the percentage of correctly answered questions in post-test decreased. It shows that the amount of students with wrong answered questioned is increased; the percentage of students with wrong answers is a sign to determine the misconceptions and their stabilities related to each item.

In Figure 2, pre- and post- test correct answers (\%) of FCI are shown. For example, item-1 of FCI is improved from $0 \%$ to $15 \%$, while for item- 4 , the improvement is from $0 \%$ to $40 \%$.

FCI pre- and post- test results from other researches were determined. The results show the percentage of students who answered FCI items correctly (Hestenes et al., 1992). For instance, in Wells Regular High School with 18 students, $28 \%$ students answered correctly in the pre-test $64 \%$ in the post-test; for Wells Honor High School with 30 students, the pre-test is $42 \%$ and post-test $78 \%$. It shows that the result of FCI depends on the level of students' ability and knowledge. Analyzing the correct answers in pre- and post- tests shows students' improvement in the teaching process. Results of our study show that the probability of guessing correct answers for the FCI questions in the pre-test is about $15 \%$. It can therefore be concluded that the students' initial 
knowledge and understanding of mechanics were very poor. This was by no means a surprise because the students had received only limited instruction in mechanics in lower secondary school. But differences in nominal value of post-test correct answers mentioned quantify the added ineffectiveness in traditional method in this study because the average improvement in results after instruction is not very considerable. In this step, we do not want to judge the benefits of traditional teaching; we are going to determine students' stable commonsense misconceptions.

\begin{tabular}{|c|c|c|c|c|c|c|c|c|c|c|c|c|c|c|c|c|c|c|c|c|c|c|c|c|c|c|c|c|c|c|c|c|}
\hline & & & & & & & & & & & & \multicolumn{8}{|c|}{ FCI items } & & \multirow[b]{2}{*}{$E$} & \multirow[b]{2}{*}{ D } & \multirow[b]{2}{*}{$E$} & \multirow[b]{2}{*}{ B } & & \multirow[b]{2}{*}{ A } & \multirow[b]{2}{*}{$c$} & \multirow[b]{2}{*}{$E$} & \multirow[b]{2}{*}{ c } & & \multirow{2}{*}{\multicolumn{2}{|c|}{$B$}} \\
\hline & & versol & $c$ & $A$ & $c$ & E & $B$ & $B$ & $B$ & $B$ & $E$ & $\bar{A}$ & 0 & $B$ & 0 & 0 & $A$ & $A$ & $B$ & B & & & & & & & & & & $E$ & & \\
\hline & $\mathrm{FCl}$ & $P_{0}$ & 1 & 2 & 3 & 4 & 5 & 6 & 7 & 8 & 9 & 10 & 11 & 12 & 13 & 14 & 15 & 16 & 17 & 18 & 19 & 20 & 21 & 22 & 23 & 24 & 25 & 26 & $2 T$ & 28 & 29 & 30 \\
\hline & & $A$ & 10 & 20 & 0 & 55 & 10 & 25 & 40 & 40 & 10 & 30 & 0 & 0 & 30 & 50 & 20 & 35 & 16 & 5 & 5 & 37 & 25 & 42 & 47 & 16 & 15 & 32 & 10 & 5 & 25 & 5 \\
\hline \multirow{6}{*}{ Post } & & B & 15 & 15 & 45 & 0 & 10 & 45 & 10 & 15 & 30 & 30 & 20 & 30 & 50 & 40 & 5 & 15 & 47 & 35 & 5 & 11 & 45 & 26 & 5 & 16 & 30 & 42 & 40 & 0 & 55 & 5 \\
\hline & & $c$ & 15 & 25 & 35 & 5 & 25 & 25 & 0 & 0 & 35 & 10 & 70 & 35 & 10 & 10 & 60 & 50 & 0 & 0 & 40 & 47 & 15 & 0 & 21 & 47 & 0 & 5 & 45 & 10 & 5 & 20 \\
\hline & & $D$ & 40 & 25 & 5 & 0 & 5 & 5 & 10 & 30 & 5 & 30 & 10 & 30 & 10 & 0 & 15 & 0 & 37 & 5 & 50 & 0 & 10 & 32 & 26 & 11 & 15 & 11 & 0 & 75 & 15 & 0 \\
\hline & & $E$ & 20 & 15 & 15 & 40 & 50 & 0 & 40 & 15 & 20 & 0 & 0 & 5 & 0 & 0 & 10 & 0 & 0 & 55 & 0 & 5 & 5 & 0 & 0 & 11 & 40 & 11 & 5 & 10 & 0 & 70 \\
\hline & & Pre & & & & & & & & & & & & & & & & & & & & & & & & & & & & & & \\
\hline & & $\bar{A}$ & 5 & 10 & 0 & 90 & $2 !$ & 24 & 25 & 40 & 25 & 20 & 0 & 0 & 10 & 45 & 15 & 10 & 40 & 0 & 15 & 67 & 5 & 5 & 40 & 40 & 0 & 53 & 37 & 0 & 21 & 0 \\
\hline \multirow{4}{*}{ Pre } & & B & 50 & 30 & 58 & 0 & 5 & 59 & 45 & 5 & 40 & 5 & 30 & 45 & 45 & 35 & 30 & 25 & 5 & 5 & 5 & 0 & 60 & 21 & 15 & 0 & 22 & 5 & 21 & 29 & 5 & 16 \\
\hline & & $c$ & 0 & 20 & 11 & 10 & 37 & 12 & 5 & 5 & 5 & 30 & 45 & 25 & 20 & 20 & 20 & 55 & 20 & 50 & 10 & 22 & 20 & 21 & 10 & 35 & 0 & 11 & 26 & 24 & 5 & 5 \\
\hline & & 0 & 30 & 15 & 16 & 0 & 11 & 0 & 0 & 10 & 15 & 30 & 15 & 20 & 15 & 0 & 35 & 10 & 25 & 30 & 55 & 0 & 5 & 21 & 30 & 5 & 28 & 26 & 11 & 18 & 53 & 16 \\
\hline & & $E$ & 15 & 25 & 16 & 0 & 26 & 6 & 25 & 40 & 15 & 15 & 10 & 10 & 10 & 0 & 0 & 0 & 10 & 15 & 15 & 11 & 10 & 32 & 5 & 20 & 50 & 5 & 5 & 29 & 16 & 63 \\
\hline
\end{tabular}

Figure 1. Analyzing correct and incorrect answers in pre- and post- tests of FCI items (\%) (Colored parts in the chart show the percentage of correct answers of students to each item).

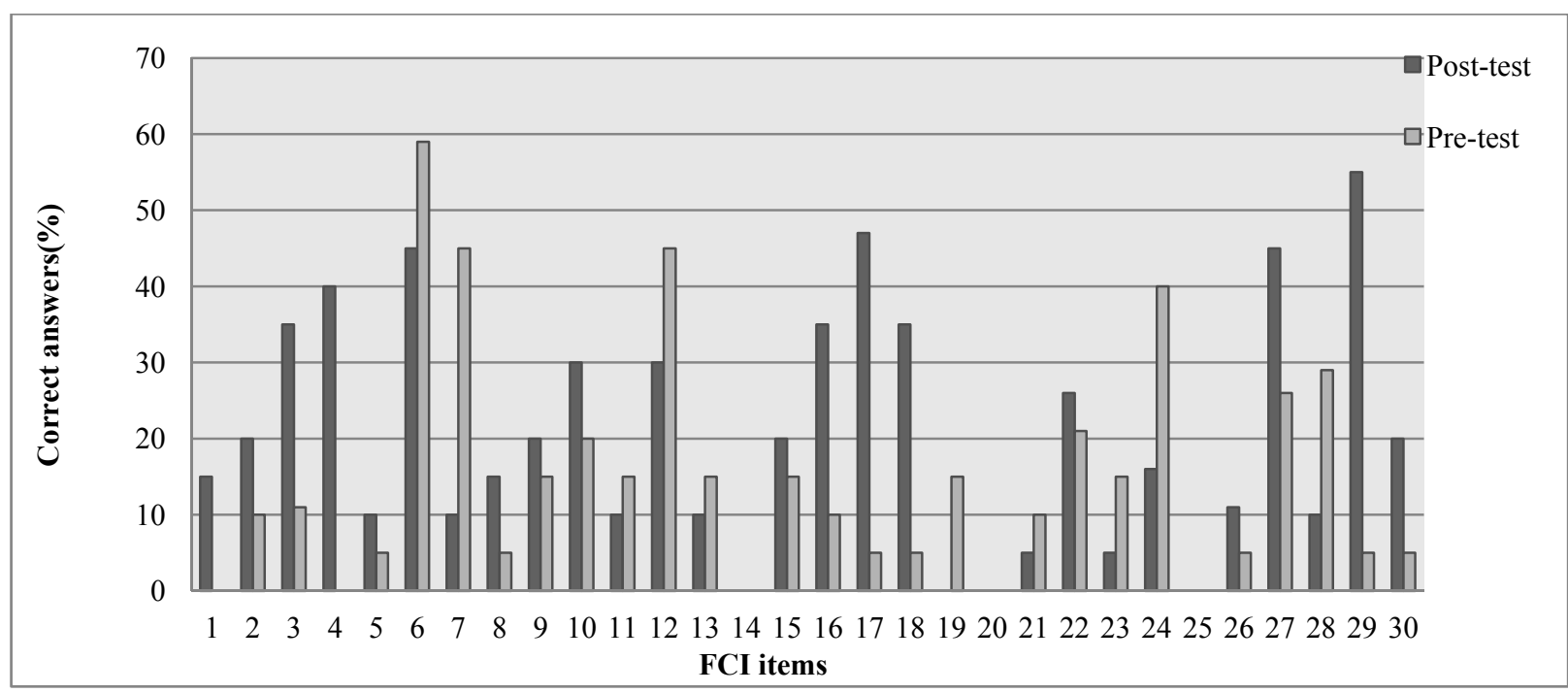

Figure 2. Correct answers (\%) of FCI items.

Table 1

Class Average in Pre-test and Post-test

\begin{tabular}{lcc}
\hline & Pre-test (\%) & Post-test (\%) \\
\hline Class average & 15 & 21 \\
$S D$ & 5 & 7 \\
Count & 20 & 20 \\
\hline
\end{tabular}

Notes. Pre-test $=15 \% \pm 5 \% S D$; post-test $=21 \% \pm 7 \% S D$.

In the next steps, we focus on incorrect responses of FCI items in pre- and post- tests. We investigate 
another comparison of results, considering the highest percentage of incorrect answers of each FCI item to study the common misconceptions after and before instruction. FCI consists of 30 items which are related to different parts of mechanics. Table 2 contains taxonomy of commonsense misconceptions probed by the FCI (Hestenes et al., 1992). It lists distinct misconceptions along with corresponding inventory items that suggest their presence when selected. They have been grouped into some major commonsense categories, which correspond as closely as possible to the majors of Newtonian concepts (or concept dimensions). Each commonsense category contains a set of misconceptions about the corresponding Newtonian concept.

Table 2

Taxonomy of Misconceptions Probed by the Inventory. Presence of the Misconceptions Is Suggested by Selection of the Corresponding Inventory Item

\begin{tabular}{|c|c|c|c|}
\hline & & & Inventory item \\
\hline \multirow{3}{*}{ Kinematics } & \multicolumn{2}{|c|}{ K1. Position-velocity undiscriminated } & 20B, C, D \\
\hline & \multicolumn{2}{|c|}{ K2. Velocity-acceleration undiscriminated } & $20 \mathrm{~A} ; 21 \mathrm{~B}, \mathrm{C}$ \\
\hline & \multicolumn{2}{|c|}{ K3. Nonvectorial velocity composition } & $7 \mathrm{C}$ \\
\hline \multirow{5}{*}{ Impetus } & \multicolumn{2}{|c|}{ I1. Impetus supplied by "hit" } & 9B, C; 22B, C, E; 29D \\
\hline & \multicolumn{2}{|c|}{ I2. Loss/recovery of original impetus } & 4D; 6C, E; 24A; 26A, D, E \\
\hline & \multicolumn{2}{|c|}{ I3. Impetus dissipation } & 5A, B, C; 8C; 16C, D; 23E; 27C, E; 29B \\
\hline & \multicolumn{2}{|c|}{ I4. Gradual/deplayed impetus build-up } & 6D; 8B, D; 24D; 29E \\
\hline & \multicolumn{2}{|c|}{ I5. Circular impetus } & 4A, D; 10A \\
\hline \multirow{7}{*}{ Active force } & \multicolumn{2}{|c|}{ AF1. Only active agents exert forces } & 11B; 12B; 13D; 14D; 15A, B; 18D; 22A \\
\hline & \multicolumn{2}{|c|}{ AF2. Motion implies active force } & $29 \mathrm{~A}$ \\
\hline & \multicolumn{2}{|c|}{ AF3. No motion implies no force } & $12 \mathrm{E}$ \\
\hline & \multicolumn{2}{|c|}{ AF4. Velocity proportional to applied force } & $25 \mathrm{~A} ; 28 \mathrm{~A}$ \\
\hline & \multicolumn{2}{|c|}{ AF5. Acceleration implies increasing force } & $17 \mathrm{~B}$ \\
\hline & \multicolumn{2}{|c|}{ AF6. Force causes acceleration to terminal velocity } & $17 \mathrm{~A} ; 25 \mathrm{D}$ \\
\hline & \multicolumn{2}{|c|}{ AF7. Active force wears out } & $25 \mathrm{C}, \mathrm{E}$ \\
\hline \multirow{2}{*}{ Action/reaction pairs } & \multicolumn{2}{|c|}{ AR1. Greater mass implies greater force } & 2A, D; 11D; 13B; 14B \\
\hline & \multicolumn{2}{|c|}{ AR2. Most active agent produces greatest force } & $13 \mathrm{C} ; 11 \mathrm{D} ; 14 \mathrm{C}$ \\
\hline \multirow{3}{*}{$\begin{array}{l}\text { Concatention of } \\
\text { influences }\end{array}$} & \multicolumn{2}{|c|}{ CI1. Largest force determines motion } & 18A, E; 19A \\
\hline & \multicolumn{2}{|c|}{ CI2. Force compromise determines motion } & 4C; 10D; 16A; 19C, D; 23C; 24C \\
\hline & \multicolumn{2}{|c|}{ CI3. Last force to act determines motion } & $6 \mathrm{~A} ; 7 \mathrm{~B} ; 24 \mathrm{~B} ; 26 \mathrm{C}$ \\
\hline \multirow{8}{*}{$\begin{array}{l}\text { Other influences on } \\
\text { motion }\end{array}$} & \multicolumn{2}{|c|}{ CF. Centrifugal force } & 4C, D, E; 10C, D, E \\
\hline & \multicolumn{2}{|c|}{ Ob. Obstacles exert no force } & 2C; 9A, B; 12A; 13E; 14E \\
\hline & \multirow{3}{*}{ Resistance } & R1. Mass makes things stop & $29 \mathrm{~A}, \mathrm{~B} ; 23 \mathrm{~A}, \mathrm{~B}$ \\
\hline & & R2. Motion when force overcomes resistance & 28B, D \\
\hline & & R3. Resistance opposes force/impetus & $28 \mathrm{E}$ \\
\hline & \multirow{3}{*}{ Gravity } & G1. Air pressure-assisted gravity & $9 \mathrm{~A} ; 12 \mathrm{C} ; 17 \mathrm{E} ; 18 \mathrm{E}$ \\
\hline & & G2. Gravity intrinsic to mass & 5E; 9E; 17D \\
\hline & & G3. Heavier objects fall faster & $1 \mathrm{~A} ; 3 \mathrm{~B}, \mathrm{D}$ \\
\hline
\end{tabular}

In this study, we consider the pre- and post- test incorrectly answered questions to investigate commonsense misconceptions; we consider the most percentage of wrong answers to determine students' misconceptions in the pre- and post- tests. For instance, in item-3, $11 \%$ students answered it correctly in the pre-test and $35 \%$ in the post-test, but most of the students answered it incorrectly in pre-test (58\%) and post-test 
(45\%) (they selected choice B). Depending on Table 2, choice B in item-3 is a sign of commonsense misconception and it shows the wrong imagination that heavier objects fall faster. So, in item-3, we find a misconception among students before and after instruction. In item-16, most of the students did not choose choice A in item-16 (correct answer) but the other wrong selection; choice $\mathrm{C}$ shows a commonsense misconception for average of the students. It is determined by physics education researcher as a wrong imagination of impetus dissipation. Results show that about 21 items of the FCI are detected having commonsense misconceptions after and before instruction.

To gain a more detailed idea about stabilities of commonsense misconceptions in mechanics in the traditional teaching strategy, we divided FCI items to eight conceptual dimensions (see Table 3).

Table 3

Commonsense Misconceptions Detected in the FCI (Traditional Instruction)

\begin{tabular}{|l|l|l|l|}
\hline FCI items & FCI dimensions & Misconceptions (Pre-test) & Misconceptions (Post-test) \\
\hline 29 & $\mathrm{~N} 2$ & Impetus supplied by hit & - \\
\hline $21,22,26$ & $\mathrm{~N} 2, \mathrm{a} \neq 0$ & $\begin{array}{l}\text { Velocity-acceleration indiscriminating, impetus } \\
\text { supplied by hit, and loss/recovery of original impetus }\end{array}$ & $\begin{array}{l}\text { Velocity-acceleration } \\
\text { indiscriminating, only active agents } \\
\text { exert forces }\end{array}$ \\
\hline $\begin{array}{l}9,10,11,17, \\
23,24,25\end{array}$ & $\mathrm{~N} 2, \mathrm{a}=0$ & $\begin{array}{l}\text { Impetus supplied by hit, obstacles exert no force, force } \\
\text { compromise determines motion, only active agents exert } \\
\text { forces, force causes acceleration to terminal velocity, } \\
\text { mass makes things stop, active force wears out }\end{array}$ & $\begin{array}{l}\text { mass makes things stop, active force } \\
\text { wears out }\end{array}$ \\
\hline 3 & $\mathrm{~N} 2$, Free fall & Heavier objects fall faster & Heavier objects fall faster \\
\hline $4,16,28$ & $\mathrm{~N} 3$ & Circular impetus, impetus dissipation & $\begin{array}{l}\text { Circular impetus, impetus } \\
\text { dissipation, motion when force } \\
\text { overcomes resistance }\end{array}$ \\
\hline 2,12 & Projectile motion & - & $\begin{array}{l}\text { Obstacles exert no force, air } \\
\text { pressure-assisted gravity }\end{array}$ \\
\hline 5,18 & Circular motion & - & $\begin{array}{l}\text { Gravity intrinsic to mass, air } \\
\text { pressure-assisted gravity }\end{array}$ \\
\hline 19,20 & Kinematics & $\begin{array}{l}\text { Force compromise determines motion, } \\
\text { velocity-acceleration indiscriminating }\end{array}$ & $\begin{array}{l}\text { Force compromise determines } \\
\text { motion, position-velocity } \\
\text { indiscriminating }\end{array}$ \\
\hline
\end{tabular}

Depending on Table 3, the commonsense misconceptions are impetus supplied by hit, velocity-acceleration indiscriminating, position-velocity indiscriminating, loss/recovery of original impetus, force compromise determines motion, only active agents exert forces, mass makes things stop, force causes acceleration to terminal velocity, active force wears out, heavier objects fall faster, circular impetus, impetus dissipation, motion when force overcomes resistance, gravity intrinsic to mass, and obstacles exert no force. Most of misconceptions are seen after and before construction and it shows that the instruction has no good effect on students' commonsense misconceptions. In addition, some misconceptions that had not existed occurred after instruction, for instance, obstacles exert no force, air pressure-assisted gravity, and gravity intrinsic to mass. It is a very complicated situation to deal with effects of teaching on learners. These results indicate that traditional teaching was not enough effective to modify commonsense misconceptions in relation to Newton's laws and motion. The percentage of incorrect responses (21 items) with misconceptions in FCI is more than correct responses after and before instruction; it shows the stableness of misconceptions in traditional teaching. In the traditional teaching method, most of the time concepts are mentioned by teachers and because of lack of time, students are not allowed to interact with other aspects of concepts in the class. These types of concepts are 
memorized by students and, with a little change in concepts, they are not able to analyze situation to achieve a correct answer.

\section{Conclusion}

Investigating the commonsense misconceptions of force and motion in the traditional teaching strategy requires measurement of students' learning in high school. Traditional teaching method (in our definition) entails four features or components, which overlap with each other to some extent: use of texts, memorizing and algorithmic mathematical focus, no classroom interaction, and no use of lab and research-based materials. Course exams and final grades typically measure lower-level educational objectives, such as memory of facts and definitions rather than higher-level outcomes, such as critical thinking. In this study, we have examined how the traditional teaching method is being able to investigate misconceptions in force and motion concepts using the FCI diagnostic test. The suggestion is with the help of FCI, students' misconceptions could be found and it is a way to determine effects of traditional teaching method in several parts of the subject. We examined class average FCI scores of 20 students in a formal instruction class. The method used to quantify changes in performance is a definitive feature of any pre- or post- testing design. Average percentage reported here suggests that the traditional approach was successful in promoting learning in some parts of subject, but in other parts, it is not successful and we found unsuccessful cases of FCI items. Induction in the percentage of incorrect responses shows that the traditional teaching method was not effective in promoting learning and modifying misconceptions, so some commonsense misconceptions are independent to traditional instruction. It seems that the problem can be linked to three aspects of the associated parts: the limitation in instructional time and content of textbooks, no use of interactive teaching tests where an ongoing teacher's lecture focuses on development of conceptual understandings depending on context of text books, and the use of traditional teaching strategy, such as lecturing and algorithmic problem-solving in assessments and final exams and no use of lab and research-based materials.

It shows the real change necessity in curriculum. It could be a guidance to revise the physics curriculum and plan new contexts to help students think like a scientist and explore the real-life phenomena in mechanics situations.

The traditional mode of introductory physics instruction (passive student lectures and and algorithmic problem exams) is relatively ineffective in promoting students' conceptual understanding. To be more effective to gain students' conceptual understanding in high school, a big change must be occurred and using active methodology in textbooks and class environments and teaching strategies is suggested.

\section{References}

Boyle, R. K., \& Maloney, D. P. (1991). Effect of written text on usage of Newton's third law. Journal of Research in Science Teaching, 28(2), 129-139.

Brooke, D., \& Etkina, E. (2009). Force, ontology, and language. Physical Review Special Topics-Physics Education Research, 5 , 010110 .

Champagne, A., \& Anderson, J. (1980). Factors influencing the learning of classical mechanics. American Journal of Physics, 48 , 1074-1079.

Crouch, C., \& Mazur, E. (2001). Peer instruction: Ten years of experience and results. American Journal of Physics, 69(9), 970-977.

Hake, R. R. (1988). Interactive-engagement $v s$. traditional methods: A six-thousand student survey of mechanics test data for introductory physics courses. American Journal of Physics, 66(1), 64-74. Retrieved from http://www.physics.indiana.edu/ sdi/ajpv3i.pdf 
Hake, R. R. (2002, December 2-4). Assessment of physics teaching methods. Proceedings of The UNESCO-ASPEN Workshop on Active Learning in Physics, University of Peradeniya, Sri Lanka. Retieved from http://www.physics.indiana.edu/ hake/

Hestenes, D., Wells, M., \& Swackhammer, G. (1992). Force concept inventory. Physics Teacher, 30, 141-158.

McCloskey, M., Caramazza, A., \& Green, B. (1980). Curvilinear motion in the absence of external forces: Naive beliefs about the motion of objects. Science, 210, 1139-1141.

Thornton, R. K. (1997). Conceptual dynamics: Following changing student views of force and motion. In E. Redish, \& J. Rigden (Eds.), AIP Conference Proceedings (Vol. 399, pp. 913-934). New York, N.Y.: American Institute of Physics.

Viennot, L. (1979). Spontaneous reasoning in elementary dynamics. European Journal of Science Education, 11, $205-221$. 